\title{
A long-life, inexpensive urine-detection pad for conditioning of enuresis nocturna
}

\author{
WILLIAM W. FINLEY and HOYT A. SMITH \\ Children's Medical Center, Tulsa, Oklahoma 74105
}

\begin{abstract}
The construction of a urine-detection pad for use in the conditioning or "bell-and-pad" treatment of enuresis nocturna is described. The electrode pad is inexpensive, reliable, and easy to construct.
\end{abstract}

In the last few years. the conditioning treatment for enuresis nocturna has become increasingly more successful and many types of instrumentation have been used. Since the introduction of the transistor, considerable progress has been made in the development of various bedwetting alarm devices. However. the enuresis electrode pad has remained a weak link in the system.

The original Mowrer (1938) electrode pad consisted of an absorbent cotton cloth sandwiched between two sheets of wire mesh. The Mowrer sandwich pad is still $w$ idely used despite its extreme cumbersomeness. The sandwich-type pads have a short life-span, tend to short out easily, are difficult to sanitize, and are relatively insensitive to small amounts of urine.

One improvement over the original Mowrer sandwich design consists of a rubber mat with conductive metal strips attached to one side. The metal strips are arranged so that shorting across any two adjacent strips triggers the circuit. When in use, the pad is placed on the bottom sheet of the bed with the conductive strips up. Crosby (1950) and Seiger (1946) have described and utilized metal strip pads in the past. However. Coote (1965) is generally credited for developing the most satisfactory design for this pad. Coote's pad has an extremely long life, and it virtually elininates false alarms due to metal strips coming in contact directly or through perspiration. Its principle disadvantage is the initial high cost. It also requires a circuit that triggers when the resistance is reduced to $4 \mathrm{~K}$. The coote pad is not widely available in the United States, either for research or clinical use.

Due to the lack of a satisfactory pad, our laboratory has experimented with many types; most have not held up under continued rigorous use. We have developed and experimented with a number of pads, from metal laminated with cloth insulation, metal stripping held down to a rubber pad with liquid rubber. to stainless steel wire mesh strips attached to a rubber mat with silicone seal caulk (Finley, Besserman, Bennett. Clapp, \& Finley, 1973). Our present pad consists of $1 / 2$-in. flat-braid tinned copper wire adhered to a rubber mat with silicone seal caulk.
The flat braid is normally manufactured as shielding for electric cable. The pad, which fits inside a pillow case, is wired so that wetting the pillow case cover completes the circuit between two adjacent strips and triggers the arousal alarm. The pads are thin and tlexible, and pose no problems of discomfort to the sletping child. The pads are easy to fabricate, requiring about $4 \mathrm{~h}$ of labor after a little practice. Material cost for one pad is approximately $\$ 20$.

\section{CONSTRUCTION}

\section{Materials}

Materials for pad construction, along with sources of supplies. are listed in Table 1.

General Electric silicone seal caulk (No. GE 2567. 712. 12-oz caulker cartridges) are used with a caulking gun. The GE silicone seal cartridges may be purchased at most hardware stores or in larger quantities from any General Electric supply house. The silicone caulk (essentially uncured rubber) comes in a number of shades (black, silver, clear, and "hite). For reasons associated with cleaning and good hygiene. ue recommend white. Approximately two 12-0\% cartridges are required per pad. The amount required varies, depending on how thick the caulk is layered on the pad. Other materials include $1 / 2$ - and

Table 1

Parts List for Pad

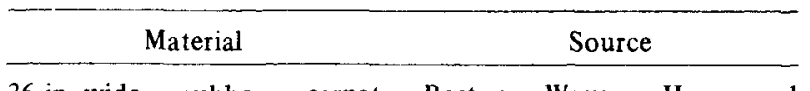

36-in.-wide rubber carpet Boston Woven Hose and matting. Stock No. 1092-36, Rubber Co., 2651 Gardner St., 23-in. roll minimum. Broadview, Ill. 60155. (Distributed by Sears-Roebuck and Co.)

No. $1233 / 2$ flat braid $1 / 2$-in. wide. No. 10AWG wire 510-in. required/pad.

No. 1229 flat braid, 96-in. required/pad

No. 1172 insulated wire. Approximately 10-ft required/ Alpha Wire Corporation, 711 Lidgerwood Ave., Elizabeth, N.J. 07207

Alpha Wire Corporation

Alpha Wire Corporation pad. 


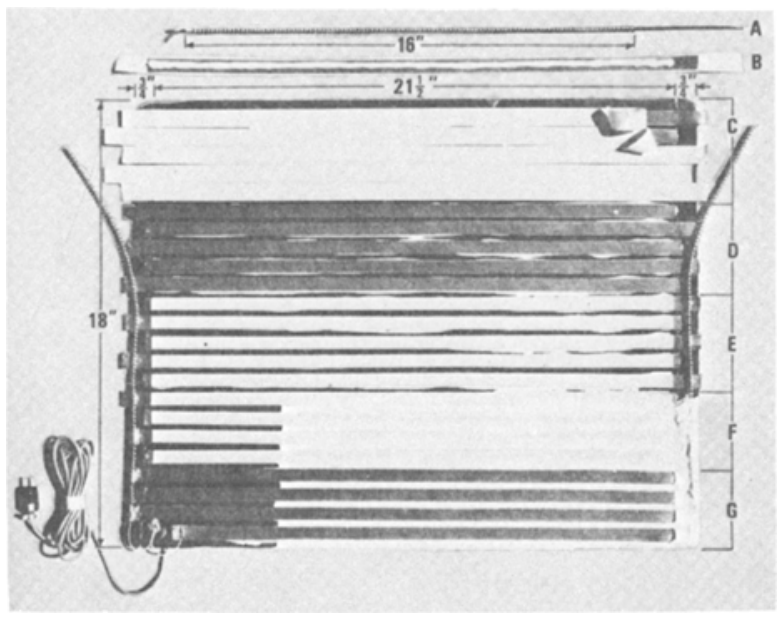

Figure 1. Enuresis pad mosaic portrays in single illustration the najor steps of construction: (A) feeder wire coiled around lotheshanger wire, (B) $1 / 2$-in. flat braid with masking tape backing and silicone seal bead drawn with caulk gun, $(C)$ conductive braid strips adhered to rubber mat, (D) braid on mat with masking tape removed, (E) overlay of $1 / 2$-in. masking tape in preparation for application of silicone seal between conductive braid strips, (F) application of silicone seal, and $(G)$ removal of protective masking tape overlay revealing finished surface of pad. The lower left portion (Steps $F$ and $G$ ) have been omitted to show wiring details.

$3 / 4$-in. masking tape to temporarily seal down the metal strips, a flattened Teflon-coated metal spatula to smooth and shape the silicone seal, and two cleaning agents: xylene and acetone.

\section{Procedure}

An $18 \times 23$ in. base for the pad is cut from rubber carpet matting. We recommend purchase of a 36 -in.-wide roll so that two 18 -in.-width pads can be made. The corners of the mats are rounded and xylene is brushed on the corrugated side. The xylene evaporates quickly, giving the rubber mat a rough, dull appearance. As a result, the uncured rubber (silicone seal) bonds more securely to the mat. Two lines are then ruled onto the corrugated side, parallel to and $3 / 4$ in. in from each 18 -in. edge. A silver or white Eagle Prismapastel pencil makes a very clear line on the corrugated rubber surface.

The next step is to cut 23 strips of Alpha flat braid (No. 1233/2, $1 / 2$ in. wide) into 22 -in.-long strips. The cut strips are placed in a pan and washed two or three times with acetone to remove a thin film of machine oil coating the braid. After the acetone evaporates from the strips, 3/4-in. masking tape is centered on one side of the strip and pressed down firmly (see Figure 1B). Silicone seal caulk is applied with a caulking gun to the other side of the metal strip in a $3 / 8$-in. ribbon (Figure $1 \mathrm{~B}$ ). The strip is then pressed down on the rubber mat with a metal spatula until the caulk is slightly squeezed out from under the edges of the metal strip (see Figure $1 \mathrm{C}$ ). The next strip is laid down adjacent to, with masking tape in contact with, the tape of the first strip. Note that the strips are alternately staggered by being lined up with the pencil line to the right and then to the left. Figure 1 shows several stages of development. Of course, strips are laid in place one at a time over the entire mat; only a small example is illustrated in Figure 1C.

Care should be taken that no silicone seal seeps between the masking tape and the braid as it is extremely difficult to remove from the braid once it has cured. The last strip is cut $1 \frac{1 / 2}{2}$ in. short to allow for a metal grommet used in the power cord connection (see Figure 1G, lower left). After the silicone seal is dry, the tape is peeled off the braid (Figure 1D). Silicone seal does not form a strong bond with masking tape.

The next step requires coiling and then soldering of the two feeder lines at each end of the pad. The Alpha No. 1229 flat braid wire is coiled by a lathe around a 1/8-in. rod at 4.25 turns/in. for 16 in. When coiling in small quantities, the braid may be hand-coiled around a straightened clotheshanger wire (Figure $1 \mathrm{~A})$. Field testing has shown that the coiled feeder line is extremely durable embedded under the silicone seal. Uncoiled braid or regular wire will kink and break after only 5 or 6 nights of use. After coiling, the clotheshanger wire is removed and the feeder line is spot soldered (resin core) to every other strip, as shown in Figures 1 and 2. Care must be taken to avoid cold solder joints that might go undetected until after the coil has been embedded under the silicone seal. The finished pad is often exposed to a surprising amount of stress and abuse. Spot solder only where the lower part of a single loop of the coil contacts the conductive strips as solder along the coil results in

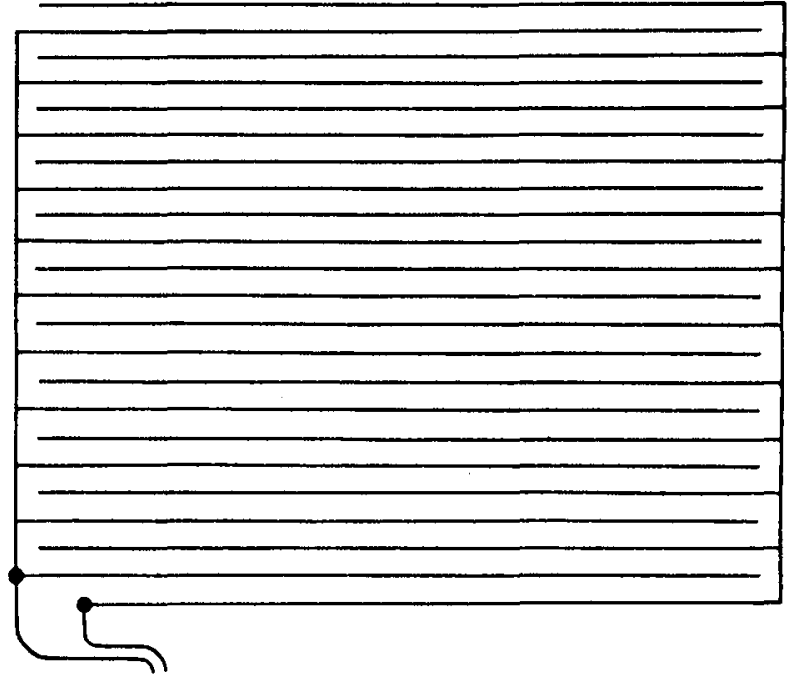

Figure 2. Wiring schematic for enuresis pad. Coiled feeder line (vertical edges of pad) supply interdigitated conductive $1 / 2 \cdot$ in. . wide braid strips. Terminal leads shown in lower left of schematic run to alarm circuitry shown in Figure 3. 
reduced flexibility and promotes breakage of the feeder line. It is important while spot soldering to avoid fraying the braid of the feeder line. The ends of the conductive strips can be bent around the feeder lines and soldered to the uppermost single loop of the coil or cut off.

A 10-ft power cord cut from Alpha No. 1172 insulated wire, or any other suitable wire depending on type of plug needed, is put through a $5 / 16$-in. metal grommet, knotted, and soldered to adjacent conductive strips (see Figures 1 and 2). The grommet is placed on the corrugated side of the mat, and the knotted power cord is strung through a hole punched in the rubber mat. The grommet and knot prevent stress on the rather delicate power cord wire and solder joints. The circuitry should be tested for continuity and shorts at this stage.

After testing. the pad is ready for a final covering of silicone seal. The conductive braid strips are covered with $1 / 2$-in. masking tape which runs to $1 / 4 \mathrm{in}$. from the end of each strip on one side and to about $1 / 2 \mathrm{in}$. from the coil on the other (Figure 1E). Silicone seal is applied between each strip by stringing a narrow bead of silicone seal and then immediately smoothing it down with a flat-ended spatula (Figure 1F); a little practice on a small sample would be of value. A bead drawn too small leaves unfilled crevices; too much seal covers the masking tape. After completing three strips, the masking tape is immediately removed as silicone seal sets quickly (Figure 1G). After the silicone seal cures for an hour or so. the conductive braid strips may be remasked and another layer of silicone seal applied. This step may be repeated as often as desired and results in the conductive metal braid being recessed below the surface of the pad. The advantage of recessing the braid is that pad resistance is unlikely to be lowered by perspiration. thus resulting in a false alarm. It is important during this stage of fabrication to keep the smoothing spatula clean and free of excess silicone seal which tends to clump on the spatula, leading to ridges and bumps on the surface of the pad. Excess silicone seal from the taped strips and from the spatula may be applied to the ends around the feeder line coils. After the silicone seal has cured for about $24 \mathrm{~h}$. the feeder coils are ready to be completely embedded. The feeder line area is masked off and then coated with silicone seal. The ends are shaped and smoothed with the spatula and then allowed to cure for at least $24 \mathrm{~h}$ before use.

The tinished pad is durable and relatively trouble free. In the event of breakage of a soldered joint beneath the cured silicone seal, the cured caulk may be cut away with a sharp razor blade. Such repairs are relatively rare once all steps in construction are mastered. Repairs are generally easy to make.

Twenty of these pads have been in constant nightly use for nearly 2 years. Literally hundreds of wettings

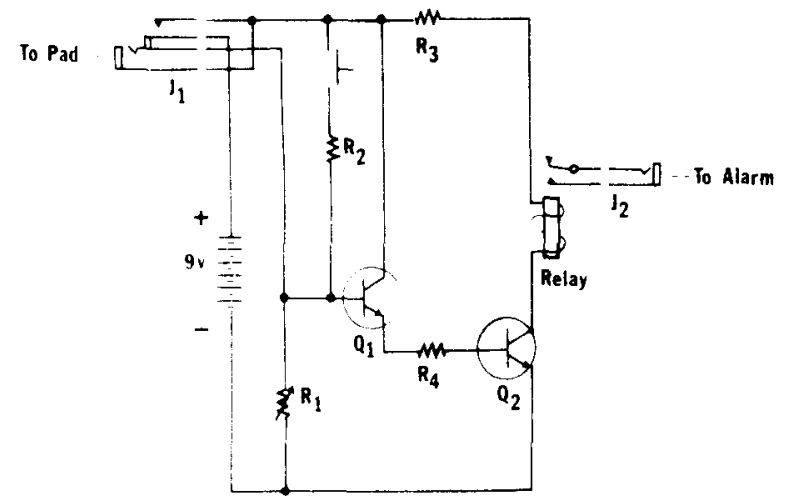

Figure 3. Enuresis detection and alarm circuit. Jack $J_{1}$ serves as both jack and switch so that whenever pad is plugged in, detection circuit is activated ready to detect a wetting. Jack $J_{2}$ goes to alarm apparatus which may be a bell, buzzer, etc. Jack $\mathrm{J}_{2}$ may also be connected to an event marker, e.g., on an EEG polygraph to record an enuretic episode and associated EEG activity.

have been reliably detected. The pads have proven to be substantially free from problems of shorting due to direct contact of metal strips or through perspiration. After proper cleaning, the pads are reusable.

The pads should be disconnected from the alarm system and thoroughly cleaned in warm soapy water at least twice a week. After each wetting, the pad is dried with an absorbent cloth using a blotting rather than a wiping action. A clean damp cloth should then be used to remove urine residue, and the pad again blotted dry with a clean dry cloth. The recommended cleaning procedures are necessary to maintain proper sanitary conditions and to protect the device from the highly corrosive effects of urine.

The pad is compatible with a number of different circuit designs (Azrin. Bugle, \& O'Brien, 1971; Herreshoff. 1973). A simple enuresis detection alarm circuit is shown in Figure 3. Typically, our instruments are set to respond when resistance through the pad drops below $30 \mathrm{~K}$. This resistance is usually achieved with a single drop of urine $(0.1 \mathrm{cc})$ shorting across a pad enclosed in a pillowcase. Circuit parts are listed in Table 2.

Urine sensitivity can vary as a function of several factors. including how deep the flat metal braid is recessed below the silicone rubber surface.

Table 2 Parts List for Circuit

$\begin{array}{ll}\text { Relay } & \text { Sigma } 65 \mathrm{~F} 1 \mathrm{~A}-6 \mathrm{DC} \\ \text { Battery } & \text { Small transistor 9-V radio battery } \\ \mathrm{J}_{1} & \text { Mallory Type } 703 \\ \mathrm{~J}_{2} & \text { Any two-wire jack that will not connect } \\ & \text { with plug to } \mathrm{J}_{1} \\ \mathrm{Q}_{1}, \mathrm{Q}_{2} & 2 \mathrm{~N} 5172 \\ \mathrm{R}_{1} & 5 \mathrm{~K} \text { trim potentiometer TWR-U201R502B } \\ \mathrm{R}_{2}, \mathrm{R}_{4} & 4.7 \mathrm{~K} \pm 10 \% 1 / 2 \mathrm{~W} \\ \mathrm{R}_{3} & 270 \Omega \pm 10 \% 1 / 2 \mathrm{~W}\end{array}$


With the circuit shown in Figure 3. battery life can be quite long. Depending on battery shelf-life, with one wetting incident per night soaking the pad for $2 \mathrm{~min}$, the battery should last about 14-18 months.

There are two apparent limitations to our pad design. First, the size is somewhat smaller in surface area than some of the commercial products available. Young children sometimes migrate off the pad, so larger pads may be required. We have found that a young child may easily be corralled or restricted to the pad by taping toy wooden blocks to the top sides of the bed mattress. This procedure makes it uncomfortable for the child to sleep off of the pad. Second, our material costs are approximately $\$ 20$; SearsRoebuck and Co. sells two Wee-Alert refill pads for \$4.95. Unfortunately. the Sears Wee-Alert pads are of the sandwich design and have to be replaced regularly. The pad described in this paper is far more sensitive. less cumbersome to use, and has a long life-span. characteristics which quickly oftset the initial effort and cost of construction.

\section{REFERENCES}

Azrin, N. H., Bugle, C., \& O'Brien, F. Behavioral engineering: Two apparatuses for toilet training retarded children. Journal of Applied Behavior Analysis. 1971. 4, 249-253.

CootE, M. A. Apparatus for conditioning treatment of enuresis. Behavior Research and Therapy. 1965. 2. 233-238.

Crosby. N. Essential enuresis: Successful treatment based on physiological concepts. Medical Journal of Australia. 1950, 2. 533-543.

Finley, W. W., Besserman, R. L., Bennett, L. F., Clapp, R. K., \& FINLEY, P. M. The effect of continuous, intermittent. and "placebo" reinforcement on the effectiveness of the conditioning treatment for enuresis nocturna. Behavior Research and Therapy, 1973. 11. 289-297.

HerReshofF, J, K. Two electronic devices for toilet training. Menal Retardation. December 1973, 54-55.

Mowrer. O. H. Apparatus for the study and treatment of enuresis. American Joumal of Psychology, 1938, 51, 163-166.

SEIGER. H. W. A practical urine or wet diaper signal. Journal of Pediatrics, 1946, 28, 733-736.

(Received for publication January 10, 1975; revision received February 22, 1975.) 